\title{
Review of Fluid Flow and Heat Transfer through Microchannels
}

\author{
Mohd Islam, Misba Jan $^{2}$ \\ Department of Mechanical Enigineering, Jamia Millia Islamia, New Delhi (India)
}

\begin{abstract}
This paper reveals the brief study of fluid flow and heat transfer characteristics in microchannels. The discussion begins with the parametric analysis of fluid flow through microchannels. This is followed by the review of heat transfer at microscale level and the description of factors which directly or indirectly affect the heat transfer rate. The paper signifies the various conditions and configurations which somehow affect the flow and heat transfer characteristics in microchannels. The paper further focusses on the recent techniques used for enhancing the heat transfer at microlevel. The paper presents a brief review of recent research initiatives in the field of microchannels. The application of fluid flow in microchannels is used for thermal management in the various fields which include biotechnology, aerospace, mechatronics and microelectronic devices. The review is largely based upon the research results reported during last few decades.
\end{abstract}

Keywords: Fluid flow characteristics, heat transfer rate and microchannels

\section{Introduction}

Fluid flow and heat transfer in channels with very small hydraulic mean diameters have been of interest for quite sometime, it has only been recently that the study of microscale phenomena in engineering has gained importance.

Small-scale channels are defined in terms of the hydraulic diameter. Microchannels are the channels for which largest dimension of the polygonal cross-section is below $1 \mathrm{~mm}$ and have hydraulic diameters ranging between $10 \mu \mathrm{m}$ and $200 \mu \mathrm{m}$ [1]. An intensive research in this field has gained significance in practical applications involving conduction and radiation in thin films, microscale structures in electronics and microscale cooloing options for the thermal management of microelectronic devices and systems. In the early 1980s, Tuckermann and Pease [1] introduced the concept of microchannel heat sinks. This discovery unfolded an entirely new research area and it was followed by many more researches. The following section describes various researches done in the field of heat transfer and fluid flow characteristics in microchannels.

\subsection{Fluid Flow Characteristics}

Flow in microchannels differ from the macroscopic scale for two reasons (a) small scale makes molecular effects predominant and, (b) amplifies the magnitudes of some ordinary continuum parameters to extreme levels. Experimental studies of microchannel flow have often failed to depict the expected relationship between friction factor and Reynolds number. The frictional resistance of flow under certain conditions has been reported to be consistent with predictions based on conventional macroscale theory. In 1981, Tuckerman and Pease studied flow through an array of microchannels with approx. rectangular cross-section. Their study focussed mainly on heat transfer characteristics, yet they confirmed that the flow obeyed macroscale theory. In 1983, Wu and Little studied microchannels for use in Joule-Thomson refrigerators. Significant roughness were present but friction factors measured in smoothest channel agreed with macroscale theory. A no. of experiments for the flow of Newtonian fluid have shown agreement with macroscale theory -in circular microtubes [Celata et al.,2002; Jiang et al.,1995; Judy et al.,2002; Li et al.,2003; Phares and Smedley,2004; Sharp and Adrian,2004], for rectangular microchannels [Judy et al.,2002; Liu and Garimella,2004], for trapezoidal cross-sections [Flockhart and Dhariwal,1998; Wilding et al.,1994]. In circular fused silica microchannels with diameter ranging from 50 to 250 microns and Reynolds no. less than 1800, the results has been reported in agreement with macroscale theory [Sharp and Adrian,2004]. Similar results have been obtained for smooth circular microtubes with diameters of 80 to 200 microns [Liu et al.,2003]. Moreover, cicular microtubes with diameter of 130 microns [Celata et al.,2002], circular and square microtubes with diameter/ hydraulic diameter from 15 to 150 microns and Reynolds no. from 8 to 2300 [Judy et al.,2002], smooth circular tubes with diameters 119 and 152 microns [Phares and Smedley,2004] and rectangular channels with hydraulic diameter ranging from 244 to 974 microns [Liu and Garimella,2004] have been revealed to be in good agreement with macroscale theory.

In some cases the frictional resistance of flow has increased as compared to conventional macroscale predictions increase by 38\% [Qu et al.,2002], increase by 37\% [Li et al.,2003], increase by 27\% [Brutin and Tadrist,2003].

In certain situations the frictional resistance of flow has decreased in comparison with macroscale approach [Choi et al.,1991; Peng et al.,1994; Pfahler et al.,1990a,1990b,1991; and Yu et al.,1995]. 


\section{International Journal of Science and Research (IJSR) \\ ISSN (Online): 2319-7064}

Index Copernicus Value (2013): 6.14 | Impact Factor (2015): 6.391

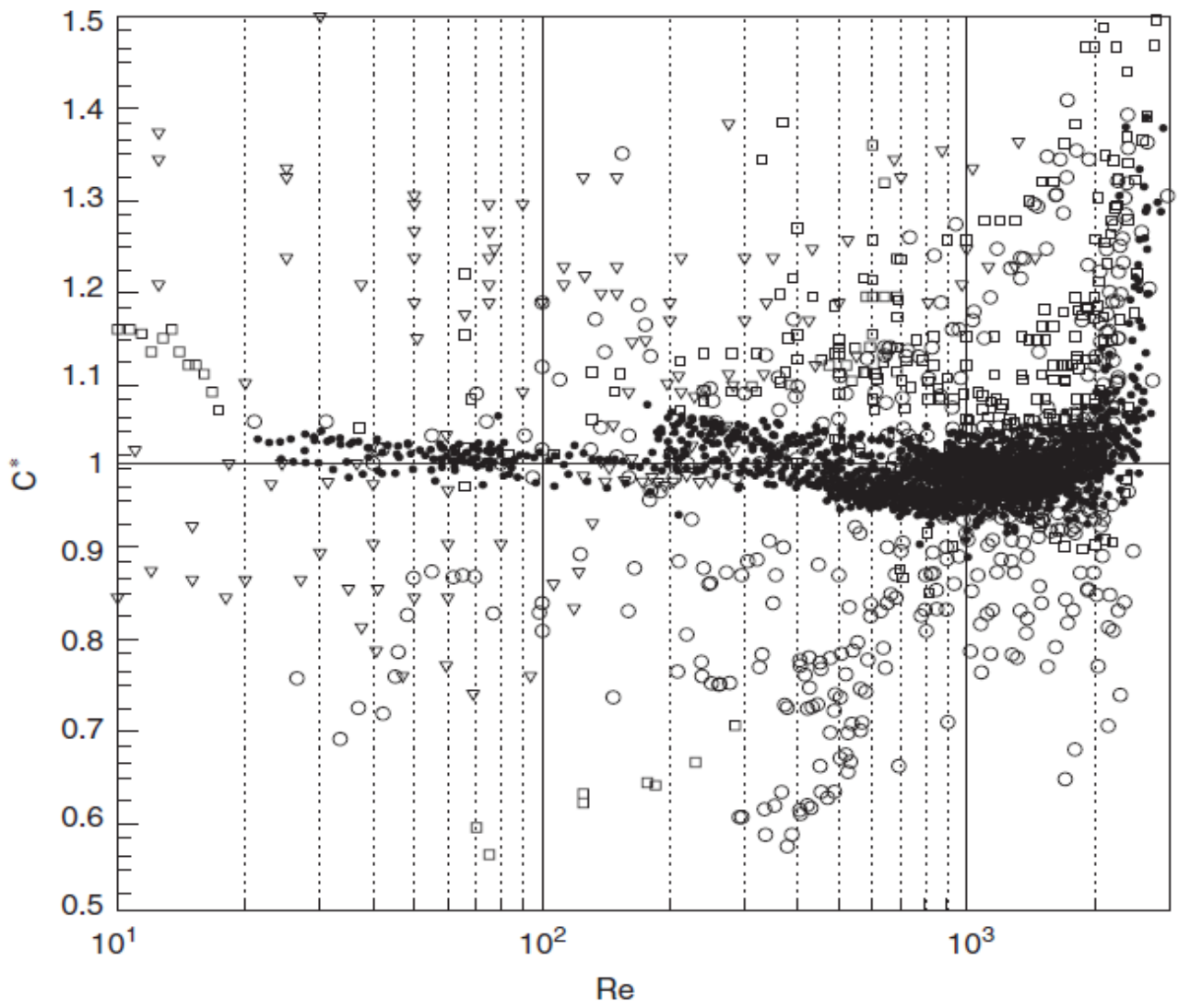

Figure 1: Symbols indicate geometry of channel: ( ) circular microtubes, Sharp \& Adrian,2004; (o) circular microtubes, Judy et al.,2002; $(\Delta)$ trapezoidal microchannels, Qu et al.,2000; ( $\square$ ) rectangular microchannels, Liu \& Garimella,2004.

Above all, it can be concluded that the conventional theory for macroscale phenomena can be applied to smooth-walled microchannels. However, there is a need for more research in order to make conclusions about the effect of surface roughness on friction factor and turbulent flow in microchannels.

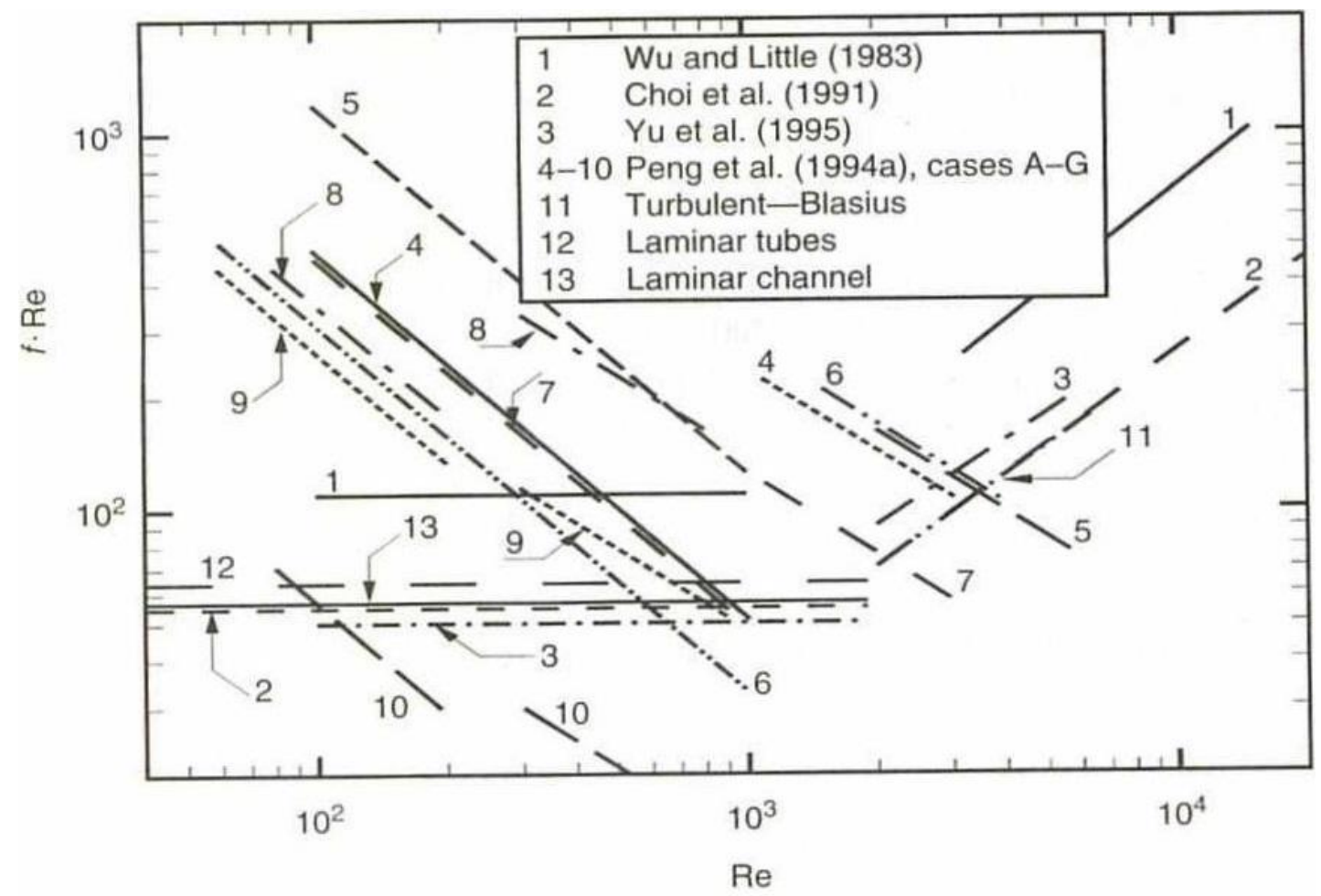

Figure 2. Comparison of the fluid friction characteristics from various investigations on convective flow in microchannels (From Sobhan, C.B. and Garimella, S.V., Microscale Thermophys. Eng., 5, 293, 2001.) 


\section{International Journal of Science and Research (IJSR) ISSN (Online): 2319-7064 \\ Index Copernicus Value (2013): 6.14 | Impact Factor (2015): 6.391}

\subsection{Heat Transfer}

A brief summary of early investigations on microchannel heat transfer is presented in this section. In 1984, Wu and Little tested trapezoidal microchannels with $\mathrm{W}=130-300$ $\mu \mathrm{m}, \mathrm{H}=30-60 \mu \mathrm{m}, \mathrm{D}_{\mathrm{h}}=55-76 \mu \mathrm{m}$ and provided $\mathrm{a}$ correlation for Nusselt number in the turbulent regime. In 1991, Choi et al. performed some experiments on microtubes with $\mathrm{D}=3,7,10,53,81 \mu \mathrm{m}, \mathrm{L}=24-52 \mathrm{~mm}$ and revealed correlations for friction factor and Nusselt number for laminar and turbulent flows.

In 1993, Peng and Wang tested rectangular stainless steel microchannels with $\mathrm{W}=0.6 \mathrm{~mm}, \mathrm{H}=0.7 \mathrm{~mm}, \mathrm{~T}_{\mathrm{i}}=30^{\circ} \mathrm{C}-$ $60^{\circ} \mathrm{C}, v=0.2-2.1 \mathrm{~m} / \mathrm{s}$ and observed a steep increase in wall heat flux with the wall temperature in case of single-phase convection; and heat flux for microchannels was higher than those for normal-size tubes. In 1995, Peng and Peterson tested water and methanol in rectangular microchannels with $\mathrm{W}=0.2,0.4,0.6,0.8 \mathrm{~mm}, \mathrm{H}=0.7 \mathrm{~mm}, \mathrm{~T}_{\mathrm{i}}=11^{\circ} \mathrm{C}-28^{\circ} \mathrm{C}$ (water), $12^{\circ} \mathrm{C}-20^{\circ} \mathrm{C}$ (methanol), $v=0.2-2.1 \mathrm{~m} / \mathrm{s}$ (water), 0.2$1.5 \mathrm{~m} / \mathrm{s}$ (methanol) and observed that changes in flow regimes and heat transfer modes initiated at lower $\mathrm{Re}$ in microchannels compared to conventional channels; and transition zone and heat transfer characteristics in laminar and transition flow were influenced by liquid temperature, velocity, Re, and microchannel size. In 1999, Adams et al. tested noncircular microchannels with $\mathrm{D}_{\mathrm{h}}=1.134 \mathrm{~mm}, \mathrm{Re}=$ $3.9 * 10^{3}-2.14 * 10^{4}, \quad$ Pr $=1.22-3.02$ and computed experimental Nusselt number and proposed $\mathrm{D}_{\mathrm{h}}=1.2 \mathrm{~mm}$ as reasonable lower limit for applicability of standard Nusselttype correlations to noncircular channels.

In 1994, Bowers and Mudawar tested circular microchannels with $\mathrm{D}=2.45 \mathrm{~mm}$ (mini), $510 \mu \mathrm{m}$ (micro), $\mathrm{Q}=19-95$ $\mathrm{ml} / \mathrm{min} ., \quad \Delta \mathrm{T}=10^{\circ} \mathrm{C}-32^{\circ} \mathrm{C}$ and identified that the accelaeration resulting from evaporation was a major contributor to pressure drop; compressibility effect played important role for microchannel when Mach number $>0.22$; and channel erosion effects were more predominant in microchannels than in mini channels. In 1996, Peng et al. tested rectangular microchannels with $\mathrm{W}=0.1,0.2,0.3,0.4$ $\mathrm{mm}, \mathrm{H}=0.2,0.3 \mathrm{~mm}, \mathrm{~L}=45 \mathrm{~mm}, \mathrm{D}_{\mathrm{h}}=0.133-0.343 \mathrm{~mm}, v$ $=0.1-0.4 \mathrm{~m} / \mathrm{s}, \mathrm{T}_{\mathrm{i}}=18^{\circ} \mathrm{C}-27.5^{\circ} \mathrm{C}$ (subcooling: $38^{\circ} \mathrm{C}-82^{\circ} \mathrm{C}$ ) and concluded that the heat transfer coefficient at onset of flow boiling and in partial nucleate boiling were greatly influenced by concentration, microchannel dimensions, flow velocity and subcooling but these parameters had no significant effect on heat transfer coefficient in the fully nucleate boiling regime; and mixtures with small concentrations of methanol augmented flow boiling heat transfer. In 1998, Peng et al. tested water and methanol in Vshaped microchannels with groove angle $=30^{\circ}-60^{\circ}, \mathrm{D}_{\mathrm{h}}=0.2$ $0.6 \mathrm{~mm}, v($ water $)=0.31-1.03 \mathrm{~m} / \mathrm{s}, v($ methanol $)=0.12-2.14$ $\mathrm{m} / \mathrm{s}$ and concluded that the heat transfer and pressure drop were affected by flow velocity, subcooling, $\mathrm{D}_{\mathrm{h}}$, and groove angle; no bubbles were observed in microchannels during flow boiling, unlike in conventional channels.

In 1996, Mertz et al. tested water and R141b in rectangular copper microchannels with $\mathrm{W}=1,2,3 \mathrm{~mm}, \mathrm{H} / \mathrm{W}<3, \mathrm{~m}=$ $50,200,300 \mathrm{~kg} / \mathrm{m}^{2} \mathrm{~s}$ and obtained boiling curves and variations of heat transfer coefficient with local and average heat fluxes.

In 1996, Cuta et al. tested rectangular microchannels with W $=0.27 \mathrm{~mm}, \mathrm{H}=1 \mathrm{~mm}, \mathrm{D}_{\mathrm{h}}=425 \mathrm{~mm}, \mathrm{ReD}_{\mathrm{h}}=100-750, \stackrel{\mathrm{q}}{<}<$ $40 \mathrm{~W} / \mathrm{cm}^{2}$ and showed that Nusselt number increased with Reynolds number in 1- $\phi$ flow, but was approximately constant in 2- $\phi$ flow.

In 1999, Gilot et al. tested water and FC72 in rectangular copper microchannels with $\mathrm{W}=230-311 \mu \mathrm{m}, \mathrm{H}=730,3040$ $\mu \mathrm{m}, \mathrm{Q}(\mathrm{ml} / \mathrm{min})=1350$ (water, $1-\phi)$ and $30(2 \phi), 2000$ (FC72 1- $\phi$ ) and 300 (2- $\phi$ ) and concluded that the two-phase heat exchanger provided lower thermal resistance and pressure drop compared to single-phase heat exchangers.

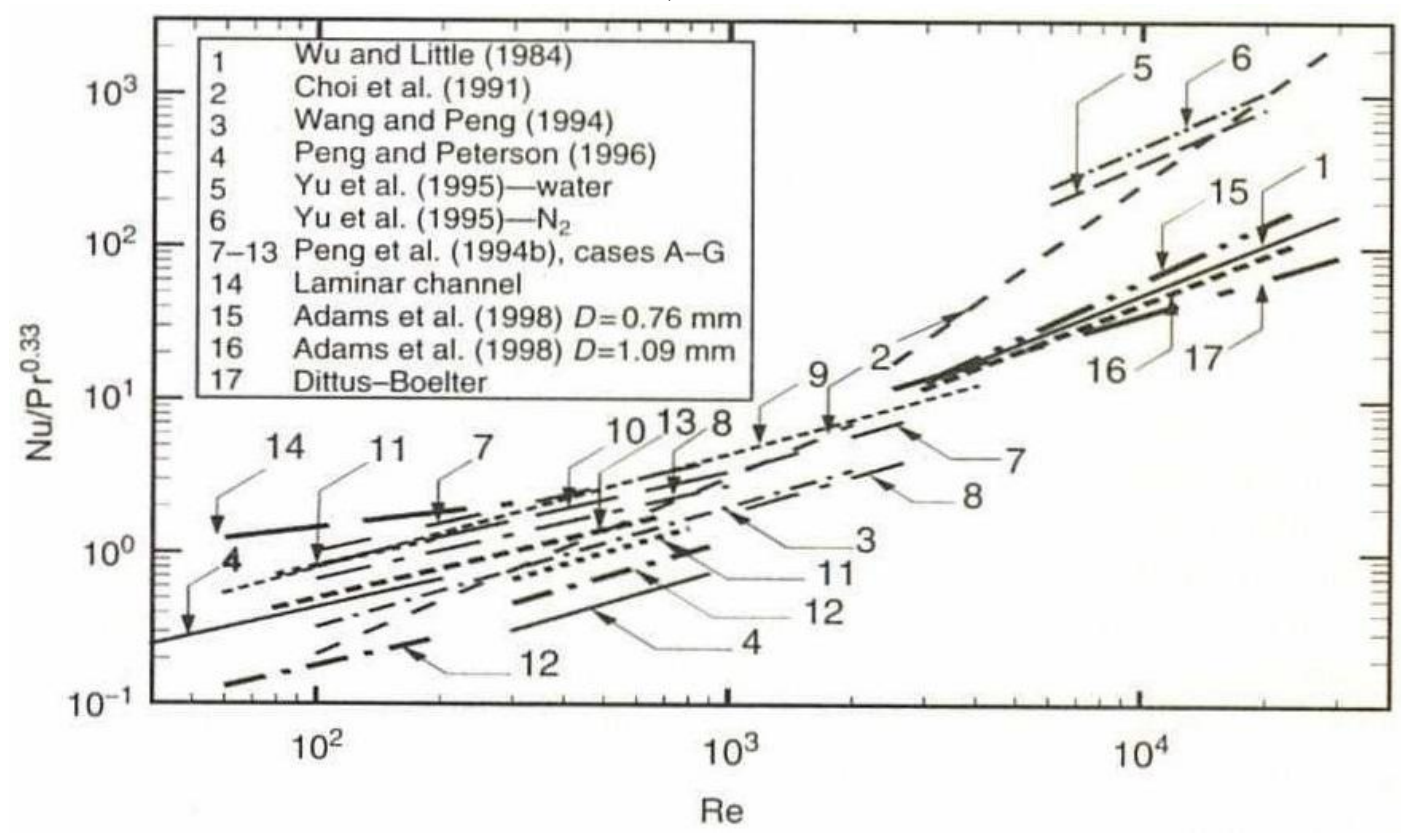

Figure 3: Comparison of the heat transfer characteristics from various investigations on convective flow in microchannels.

(From Sobhan, C.B. and Garimella, S.V., Microscale Thermophys. Eng., 5,293, 2001.) 


\section{International Journal of Science and Research (IJSR) \\ ISSN (Online): 2319-7064 \\ Index Copernicus Value (2013): 6.14 | Impact Factor (2015): 6.391}

Qu et al. (2000) reported on experimental investigations of the flow of water in trapezoidal silicon microchannels with hydraulic diameters ranging from 62 to $169 \mu \mathrm{m}$. A significant difference was found between the theoretical predictions and the experimental results, in which the experimental Nusselt numbers were found to be much lower than the values as predicted using conventional techniques. Zhao and Lu (2002) performed analytical and numerical investigations of forced convection in microchannel heat sinks. Two approaches, namely the fin approach and the porous medium model, were utilized in the analysis. Predictions from both the approaches showed that the overall Nusselt number increased with an increase in the aspect ratio and a decrease in the effective thermal conductivity ratio. Azimian and Sefid (2004) reported results of a 3-D computational analysis of the flow of Newtonian and non-Newtonian fluids in microchannels. It was found that the pressure drop was significantly reduced and the Nusselt number was increased for shear thinning fluids. The reverse was true for shear thickening fluids. Maynes and Webb (2003) analyzed the fully developed electro-osmotically driven flow in microchannels, imposed by a voltage gradient along the length of the channel. Analytical solutions with constant wall heat flux and constant wall temperature boundary conditions, for combined pressure and electro-osmotically driven flows in microchannels, were obtained. Exact solutions of the fully developed dimensionless temperature gradient and Nusselt number were found to depend on the relative duct radius. The fully developed Nusselt number was found to depend on the duct radius to Debye length ratio, the dimensionless volumetric source, and a dimensionless parameter that characterizes the relative strengths of the two driving mechanisms- the pressure and the electro-osmotic forces. Garimella and Singhal (2004) presented experimental results and discussed the fluid flow in microchannels, focusing on the pumping capabilities and pumping power optimization for electronics cooling applications. The experimental data indicated that the conventional correlations can be used to accurately predict the fluid flow and heat transfer performance of microchannel flows, in channels with hydraulic diameters as small as $250 \mu \mathrm{m}$. Xu et al. (2005) developed a microchannel heat sink with a number of longitudinal and transverse microchannels, dividing the flow domain into several independent zones. This arrangement produced interruption and reattachment of the boundary layer, thus enhancing the heat transfer. In this investigation, the pressure drop was reduced, when compared to conventional longitudinal microchannels. In the experiments, the local chip temperature and heat fluxes were measured using a high resolution infrared temperature measuring system. An appropriate thermal resistance and a dimensionless pressure drop were both defined.

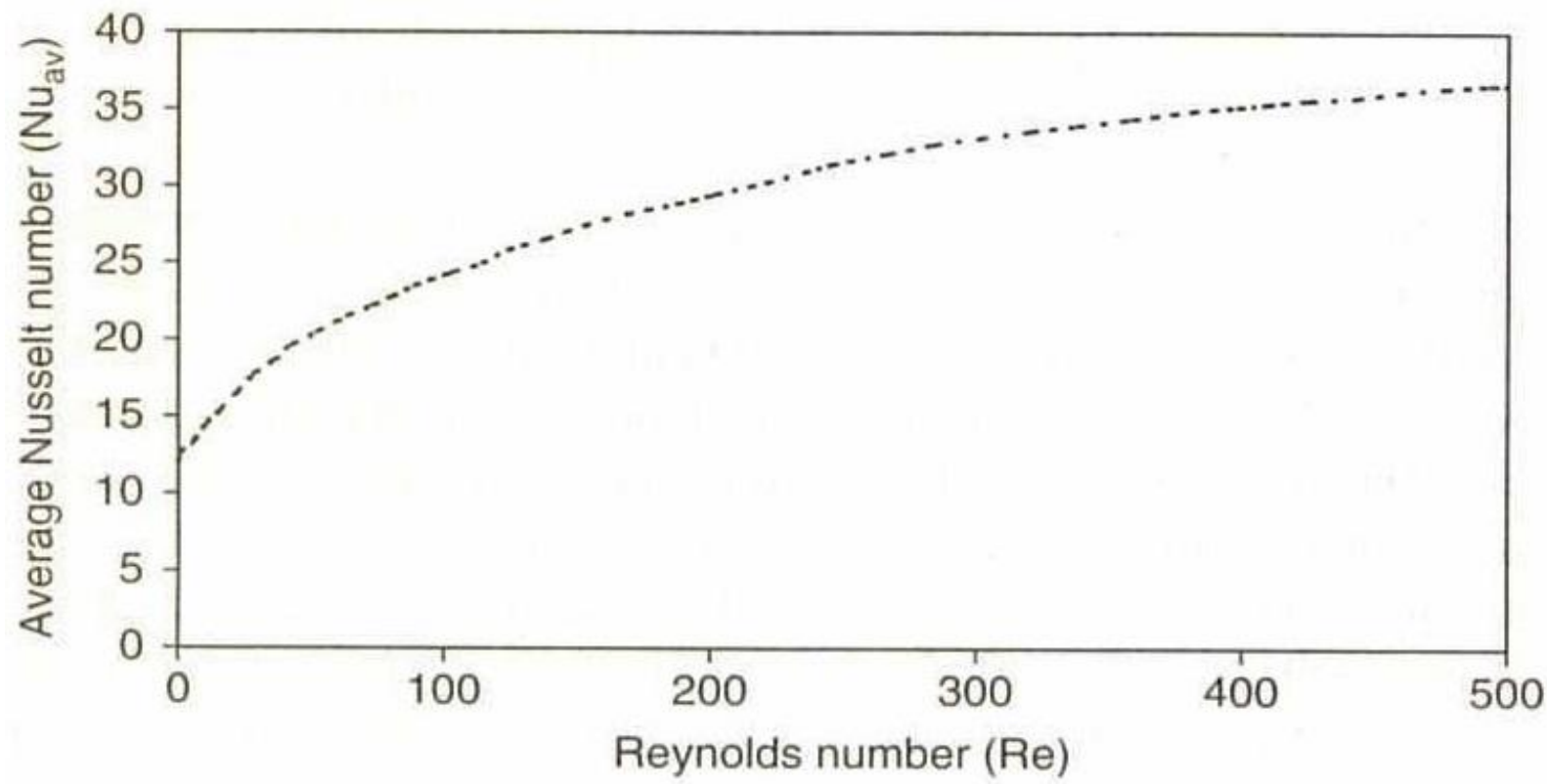

Figure 4: Variation of the average Nusselt number as a function of the Reynolds number (Adapted from Mala, M., Li, D.G., and Dale, J.D., Int. J. Heat Mass Transfer, 40, 3079, 1997.)

\section{Discussion}

From the literature survey it might be observed that the anomalies and deviations in the behaviour of microchannel flow and heat transfer were identified and compared with the results of conventional prediction techniques. Comparison of the existing experimental results, however, indicates instances where disparities have been identified among the results from various investigations.
Moreover, the discussion of the size effects of microscale single-phase flow and heat transfer, and the effect of the dominant factors such as the characteristic length has been presented. Some of the previous investigations have indicated that the cross-sectional shape of the microchannel other factors can greatly influence the flow behaviour and the resulting heat transfer capability inside the microchannels. The effects of surface roughness, variation of the dominant forces acting on the fluid flow, the axial conduction effects, and other important factors such as surface geometry and measurement accuracy, in microscale fluid flow and heat transfer data has also been reported. 


\section{International Journal of Science and Research (IJSR) \\ ISSN (Online): 2319-7064 \\ Index Copernicus Value (2013): 6.14 | Impact Factor (2015): 6.391}

\section{Conclusion}

As it is clearly evident that the interest in the field of microchannels has been growing significantly in the past decade. A number of investigations have been conducted to understand the fluid flow and heat transfer phenomena particularly for thermal management in electronic devices.

However, there is a need for extensive investigations with careful design, fabrication and instrumentation of the microchannels to examine and eliminate the resulting disparities in the observed results. Non-conventional modelling based on molecular dynamics would have to be utilised to better incorporate the problem at small length.

Moreover, phase change processes provide a much more effective mechanism of heat dissipation, such processes at the microscale will continue to be investigated to obtain more conclusive results.

\section{References}

[1] Tuckerman, D.B. and Pease, R.F.W. 1981. Highperformance heat sinking for VLSI. IEEE Electron Device Letters 2(5):126-129.

[2] Peng, X.F., Wang, B.X., Peterson, G.P., and Ma, H.B. 1995. Experimental investigation of heat transfer in flat plates with rectangular microchannels. International Journal of Heat and Mass Transfer 38(1):127-137.

[3] Peng, X.F., and Peterson, G.P. 1995. Effect of thermo fluid and geometrical parameters on convection of liquids through rectangular microchannels. International Journal of Heat and Mass Transfer 38(4):755-758.

[4] Wu, P. and Little, W.A. 1983. Measurement of friction factors for the flow of gases in very fine channels used for microminiature Joule-Thomson refrigerators. Cryogenics 23(5):273-277.

[5] Li, H., and Olsen, M.G. 2006. Aspect ratio effects on turbulent and transitional flow in rectangular microchannels as measured with micro PIV. Journal of Fluids Engineering 128:305-315.

[6] Xu, B., Ooti, K.T., Wong, N.T., and Choi, W.K. 2000. Experimental investigation of flow friction for liquid flow in microchannels. International Communications in Heat and Mass Transfer 27:1165-1176.

[7] Judy, J., Maynes, D., and Webb, B.W. 2002. Characterization of frictional pressure drop for liquid flows through microchannels. International Journal of Heat and Mass Transfer 45(17):3477-3489.

[8] Qu, W., and Mudawar, I. 2002. Experimental and numerical study of pressure drop and heat transfer in a single-phase microchannel heat sink, International Journal of Heat and Mass Transfer 45:2549-2565.

[9] Sharp, K.V., and Adrian, R.J. 2004. Transition from laminar to turbulent flow in liquid filled microtubes, Experiments in Fluids 36:741-747.

[10]Lee, P.S., Garimella, S.V., and Liu, D. 2005. Investigation of heat transfer in rectangular microchannels, International Journal of Heat and Mass Transfer 48:1688-1704.

[11] Choi, S.B., Barron, R.F., and Warrington, R.O., Fluid flow and heat transfer in microtubes, Micromechanical
Sensors, Actuators, and Systems, ASME DSC, 1991, Vol. 32, p. 123-134.

[12] Yu, D., Warrington, R., and Ameel, T. 1995. An experimental and theoretical investigation of fluid flow and heat transfer in microtubes, Proceedings of ASME/JSME Thermal Engg. Joint Conference 523-530.

[13] Adams, T.M., Abdel-Khalik, S.I., Jeter, S.M., and Qureshi, Z.H. 1998. An experimental investigation of single-phase forced convection in microchannels. International Journal of Heat and Mass Transfer 41:851-857.

[14] Celata, G.P., Cumo, M., Guglielmi, M., and Zummo, G. 2002. Experimental investigation of hydraulic and single phase heat transfer in $0.130 \mathrm{~mm}$ capillary tube. Microscale Thermo-physical Engineering 6:85-97.

[15] Azimian, A.R., and M. Sefid. 2004. Performance of microchannel heat sinks with Newtonian and nonNewtonian fluids. Heat Transfer Enigeering. 25:17-27.

[16] Brutin, D., F. Topin, and L. Tadrist. 2003. Experimental study of unsteady convective boiling in heated minichannels. International Journal of Heat and Mass Transfer46:2957-2965.

[17] Cuta, J.M., C.E. McDonald, and A. Shekarizz. 1996. Forced convection heat transfer in parallel channel array microchannel heat exchanger. Advances in Energy Efficiency, Heat/Mass Transfer Enhancement, ASME PID-2/HTD-338:17-23.

[18]Gillot, C., C. Schaeffer, and A. Bricard. 1998. Integrated micro heat sink for power multichip module. IEEE Industry Applications Society Annual Meet 2:1046-1050.

[19] Jiang, P.X., M.H. Fan, G.S. Si, and Z.P. Ren. 2001. Thermal-hydraulic performance of small scale microchannel and porous-media heat-exchangers. International Journal of Heat and Mass Transfer 44:1039-1051.

[20] Mertz, R., A. Wein, and M. Groll. 1996. Experimental investigation of flow boiling heat transfer in narrow channels. Heat and Technology 14:47-54.

[21] Pfahler, J., J. Harley, H.H. Bau, and J. Zemel. 1991. Gas and liquid flow in small channels. Micromechanical Sensors, Actuators and Systems. ASME DSC-32:49-60.

[22] Zhao, C.Y. and T.J. Lu. 2002. Analysis of microchannel heat sinks for electronics cooling. International Journal of Heat and Mass Transfer 45:4857-4869.

[23] Garimella, S.V. and C.B. Sobhan. 2003. Transport in microchannels-A critical review. Annual Review of Heat Transfer 13: 1-50.

[24] Mala, M., D.G. Li, and J.D. Dale. 1997. Heat transfer and fluid flow in microchannels. International Journal of Heat and Mass Transfer 40: 3079-3088. 